\title{
Body composition and physical activity in New Zealand Maori, Pacific and European children aged 5-14 years
}

\author{
Elaine C. Rush ${ }^{1 *}$, Lindsay D. Plank ${ }^{2}$, Peter S. W. Davies ${ }^{3}$, Patsy Watson ${ }^{4}$ and Clare R. Wall ${ }^{4}$ \\ ${ }^{1}$ Department of Applied Science, Auckland University of Technology, Private Bag, 92006, Auckland 1020, \\ New Zealand \\ ${ }^{2}$ Department of Surgery, University of Auckland, Auckland, New Zealand \\ ${ }^{3}$ Children's Nutrition Research Centre, Department of Paediatrics and Child Health, Royal Children's Hospital, \\ University of Queensland, Brisbane, Australia \\ ${ }^{4}$ Institute for Food, Nutrition and Human Health, Massey University, Auckland, New Zealand
}

(Received 14 May 2003 - Revised 8 August 2003 - Accepted 16 August 2003)

\begin{abstract}
Body fatness and the components of energy expenditure in children aged 5-14 years were investigated. In a group of seventy-nine healthy children (thirty-nine female, forty male), mean age 10.0 (SD 2.8) years, comprising twenty-seven Maori, twenty-six Pacific Island and twenty-six European, total energy expenditure (TEE) was determined over $10 \mathrm{~d}$ using the doubly-labelled water method. Resting metabolic rate (RMR) was measured by indirect calorimetry and physical activity level (PAL) was calculated as TEE:RMR. Fat-free mass (FFM), and hence fat mass, was derived from the ${ }^{18} \mathrm{O}$-dilution space using appropriate values for FFM hydration in children. Qualitative information on physical activity patterns was obtained by questionnaire. Maori and Pacific children had a higher BMI than European children $(P<0.003)$, but $\%$ body fat was similar for the three ethnic groups. The $\%$ body fat increased with age for girls $(r 0.42, P=0.008)$, but not for boys. Ethnicity was not a significant predictor of RMR adjusted for FFM and fat mass. TEE and PAL, adjusted for body weight and age, were higher in Maori than European children $(P<0 \cdot 02)$, with Pacific children having intermediate values. PAL was inversely correlated with $\%$ body fat in boys $(r-0.43, P=0.006)$, but was not significantly associated in girls. The $\%$ body fat was not correlated with reported time spent inactive or outdoors. Ethnic-related differences in total and activity-related energy expenditure that might account for higher obesity rates in Maori and Pacific children were not seen. Low levels of physical activity were associated with increased body fat in boys but not in girls.
\end{abstract}

Body composition: Doubly-labelled water: Energy expenditure: Resting metabolic rate: Ethnic differences: Gender: Physical activity: Activity questionnaire: Children

Obesity is now recognised as a disease of epidemic proportions in Westernised countries and, at least in adults, is associated with cardiovascular disease, hypertension and diabetes. In these countries the prevalence of overweight and obesity in children has increased significantly over the last 20 years (Trioano et al. 1995; Freedman et al. 1997). Obesity that occurs in childhood is known to correlate with adult obesity (Williams, 2001) and the targeting of preventative strategies to children may have important consequences for reducing the incidence of adult obesity. This increased prevalence in children can be ascribed, at least in part, to changes in physical activityrelated energy expenditure (AEE) and dietary energy and fat intake (World Health Organization, 1998).

Genotype, environment, energy intake and energy expenditure are the determinants of body composition and the maintenance of body weight. Measurement of the physical activity component of energy expenditure is problematic, as time, intensity, metabolic efficiency or physical fitness, and the intermittent nature of spontaneous activity all need to be considered (Schutz et al. 2000; Schoeller \& Jefford, 2002). Questionnaires can give a good indication of different types of activity, but do not have a direct relationship to the energy costs of activity for that individual (Kriska et al. 1990; Pate et al. 1996; Going et al. 1999). Motion sensors and accelerometers require calibration and can be obtrusive to the child's activities; direct observation of activity is also likely to bias the behaviour (Janz et al. 1995). The doubly-labelled water (DLW) method is a non-invasive measure of total energy expenditure (TEE) in the free-living subject and, when combined with a measurement of resting metabolic

\footnotetext{
Abbreviations: AEE, activity-related energy expenditure; DLW, doubly-labelled water; FFM, fat-free mass; FM, fat mass; PAL, physical activity level; RMR, resting metabolic rate; TEE, total energy expenditure.

* Corresponding author: Dr Elaine C. Rush, fax +649917 9973, email elaine.rush@aut.ac.nz
} 
rate (RMR), the TEE:RMR ratio, known as the physical activity level (PAL), is an index of physical activity (Black, 1996).

Using the DLW method in pre-school children, Davies et al. (1995) found that high \% body fat was associated with low PAL in both boys and girls. In older children (6-9 years old) Ball et al. (2001) found that this relationship held for boys, but not for girls. These studies did not examine ethnic differences. In New Zealand children aged between 5 and 11 years, those from the Maori and Pacific Island ethnic groups are more likely to be obese than their European counterparts (Tyrrell et al. 2001). Health problems that are associated with obesity, such as type 2 diabetes mellitus and CHD, are more prevalent in New Zealand Maori and Pacific Island adults than Europeans (Bathgate et al. 1994; Simmons et al. 1994; Bell et al. 1996). No study has been conducted that investigates the relationships between body fatness and physical activity in New Zealand children from these three ethnic groups. The aims of the current study of children in the years before and including puberty, i.e. 5-14 years old, were: (1) to measure TEE by DLW; (2) to examine the relationships between measures of physical activity and body fatness; (3) to examine possible ethnic and gender differences in these relationships; (4) to examine qualitative information on time spent in inactivity and physical activity in relation to measurements of body composition and energy expenditure.

\section{Subjects and methods}

\section{Subjects}

The present study, performed between May and November 2000 , formed part of a pilot study of the methods to be used in the first national survey of nutrition in New Zealand children. Eighty children aged 5-14 years were recruited to undergo DLW measurements. Quota sampling from Auckland schools and the community was used to ensure approximately equal numbers in each gender group and in the Maori, Pacific Island and European ethnic groups. Children were recruited from schools that agreed to participate after an initial written approach. Children who had any illness at the time of testing were excluded, as were children who had been resident in New Zealand $<12$ months. Only one child from each household was studied. The study protocol was explained to the parent(s) and the child, and informed, written consent was obtained from the parent and the child. The study was approved by the Auckland Ethics Committee, an accredited regional ethics committee.

\section{Protocol}

At an initial visit to the child's home after school or at weekends, body weight $( \pm 0.1 \mathrm{~kg})$ was measured using digital scales, with a correction for estimated weight of clothing, height $( \pm 1 \mathrm{~mm})$ was measured using a stadiometer, and bioelectrical impedance measurements were made. Approximately $7 \mathrm{~d}$ later a repeat visit was made during which RMR was measured, a baseline urine sample was collected and a dose of DLW was given. A further urine sample was collected $5 \mathrm{~h}$ after dosing. Over the subsequent $10 \mathrm{~d}$, timed urine samples were collected for analysis of ${ }^{2} \mathrm{H}$ and ${ }^{18} \mathrm{O}$. At the end of this period, a questionnaire was completed relating to out-of-school activity and sleeping patterns.

\section{Body composition}

Fat-free mass (FFM) was determined from the ${ }^{18} \mathrm{O}$-dilution space by assuming that this is $1 \%$ larger than total body water and by using the appropriate values for the hydration of FFM in children of different ages (Fomon et al. 1982; Lohman, 1986). Since ${ }^{18} \mathrm{O}$-space measurements were also used in the calculation of TEE as described later, an alternative measurement of FFM was obtained from bioelectrical impedance analysis. FFM was calculated using an algorithm reported elsewhere (Rush et al. 2003) from whole-body resistance determined by tetrapolar single-frequency bioelectrical impedance measurement (Model BIM4; Impedimed, Capalaba, Queensland, Australia). Fat mass (FM) was derived as the difference between body weight and FFM. The \% body fat was calculated by using FM and body weight.

\section{Resting metabolic rate}

RMR was measured using a mask measurement system (Mini-CPX; Vacumed, CA, USA). Before each measurement, calibration of this device was performed against a reference $\mathrm{O}_{2}-\mathrm{CO}_{2}$ mixture. Barometric pressure, ambient humidity and temperature measured by the device were checked against reference laboratory instruments. The manufacturers performed a full accuracy check by using a metabolic calibrator (Huszczuk et al. 1990) at the beginning of the study and again at the mid-point of the study. At the initial visit the child was shown the mask and a photograph of a person undergoing the test, and the process explained in detail. The actual test took place at a mutually agreed time in the child's home with the parent present. We sought to measure RMR under postprandial conditions ( $1-3 \mathrm{~h}$ after their usual lunch) in the afternoon after the child had returned from school. A record was kept of what the child had last eaten and when. The child lay on a couch and usually watched television or had a soothing story read to them with music in the background. At least $20 \mathrm{~min}$ of stable measurements were made. The heart rate was monitored using a finger pulse oximeter as an indicator of relaxation. Conditions similar to these for RMR measurement have been shown to be both reproducible and practical, resulting in improved compliance in children when compared with more stringent protocols (Goran \& Nagy, 1996).

\section{Total energy expenditure}

TEE was measured over a period of $10 \mathrm{~d}$ using the DLW technique. Each child was given an oral pre-weighed DLW dose $\left(0.125 \mathrm{~g} \mathrm{H}_{2}^{18} \mathrm{O}\right.$ and $0.050 \mathrm{~g}{ }^{2} \mathrm{H}_{2} \mathrm{O} / \mathrm{kg}$ body weight) via a straw in a child's sealed drinking cup followed by two rinses of bottled water. The child or parent 
was given labelled sampling containers and instructions to collect timed urine samples $5 \mathrm{~h}$ post-dose and on days 1,2 and 3 after dosing. At a later visit, sampling pots for days 8,9 and 10 after dosing and a new set of instructions and diary were given to the family. The researcher telephoned the family each day that a sample was required and arranged to collect the samples as often as convenient for the family. During this call, emphasis was placed on the importance of adhering to the instructions for collection of the urine samples. Samples were frozen until assayed for ${ }^{2} \mathrm{H}$ and ${ }^{18} \mathrm{O}$ by isotope-ratio MS in the Energy Metabolism Laboratory at the Queensland University of Technology, as described in detail elsewhere (Davies \& Coward, 1994; Rush et al. 1999). The multipoint approach was used with an assumed RQ of 0.85 over the $10 \mathrm{~d}$ period.

\section{Activity-related energy expenditure and physical activity level}

AEE was derived as the difference between TEE and postprandial RMR. To adjust for body-size effects, AEE was divided by body weight (Schoeller \& Jefford, 2002). No correction for the thermic effect of food was made when postprandial RMR was used. For those children whose last meal was $>4 \mathrm{~h}$ before the RMR measurement, a $10 \%$ increase in RMR was made (Goran \& Nagy, 1996) to allow for the dietary thermogenesis and to ensure that AEE does not include the latter component. The TEE:RMR ratio was calculated as an index of PAL.

\section{Activity questionnaire}

This questionnaire was developed for potential use in the New Zealand children's nutrition survey. The current study provided the opportunity to compare qualitative activity data with objective energy expenditure information. Each child and a parent were interviewed to obtain information relating to times of inactivity and activity outside school time. The standard requirement for physical education in the New Zealand schools' curriculum for children aged 5-16 years allowed within-school activity times to be estimated. Sleep times were determined by asking the time that the child goes to bed and the time of getting up in the week and at weekends. Time spent watching television was obtained as the average time per weekday and at the weekend. Time spent outdoors was asked in relation to exposure to the sun (vitamin $\mathrm{D}$ ) and recorded for the school week and the weekend. Activity questions for out-of-school activities were asked in relation to sittingand standing-type activities, walking and running. A 'do not wish to answer' option for all questions meant that responses were not recorded for all children.

\section{Statistical analysis}

Results are presented as mean values and standard deviations. The Kolmogorov-Smirnov test was used to assess normality of distribution. Dependent variables (energy expenditure components, body composition and time spent in activities) were analysed by two-way ANOVA using gender and ethnicity as the grouping variables, followed by Tukey's post hoc analysis. Associations between variables were examined using Pearson's correlation coefficient. Analysis of covariance was used to adjust energy expenditure results for comparison across gender and ethnic groups. Before carrying out analysis of covariance, similarity of regression slopes among the ethnic and/or gender subgroups was verified by examining the significance of the interaction between the covariate and each of the two grouping variables. Unless stated otherwise, results are reported for analyses carried out using body composition data based on ${ }^{18} \mathrm{O}$ dilution. Data were analysed using SAS software, version 6.12 (SAS Institute Inc., Carey, NC, USA). Results with $P$ values $<0.05$ were considered significant.

\section{Results}

All eighty children completed the measurements. One European male child was excluded because of an unacceptably low TEE result. Of the seventy-nine children (thirtynine female and forty male), twenty-seven (thirteen female, fourteen male) self-identified as Maori, twenty-six (thirteen female, thirteen male) as Pacific Island and twenty-six (thirteen female, thirteen male) as European. Mean age, body weight, height, BMI, FFM, FM and \% body fat for boys and girls in each ethnic group are shown in Table 1. Two-way ANOVA indicated no significant interactions between gender and ethnicity for these variables. Age, height and FFM were similar for boys and girls and for the three ethnic groups. Girls weighed more and had higher FM and \% body fat than boys. BMI differed significantly across the three ethnic groups, with both Maori and Pacific children having higher BMI than European children. Differences in FM and \% body fat between the three ethnic groups were not statistically significant. The $\%$ body fat increased with age for girls ( $r$ 0.42, $P=0.008)$, but not for boys $(r-0 \cdot 16, P=0.32)$.

Unadjusted values for RMR, TEE, AEE, AEE/weight and PAL are shown in Table 1 . There were no significant interactions between gender and ethnicity for these variables (two-way ANOVA). RMR, TEE, AEE, and AEE/ weight were similar for boys and girls. Pacific children had higher RMR than European children, with Maori children having intermediate values. After adjusting RMR for FFM and FM, neither gender nor ethnicity were significant factors. Addition of age as a covariate did not improve prediction of RMR.

Before adjustment, TEE was significantly higher in Maori and Pacific than European children. After adjustment for body weight and age, TEE remained similar for boys and girls $(P=0 \cdot 36)$ and higher in Maori (11319 (SD 2214) $\mathrm{kJ} / \mathrm{d})$ than European $(9410$ (SD 2303) kJ/d, $P=0.003)$ children, with Pacific children having an intermediate value (10708 (SD 2265) kJ/d). After adjustment for body weight and age, while there was no gender difference, AEE was significantly higher in Maori (4725 (SD 2691) $\mathrm{kJ} / \mathrm{d}$ ) than European (2744 (SD 2800) kJ/d, $P=0.012$ ) children, with Pacific children (3518 (SD 2754) $\mathrm{kJ} / \mathrm{d}$ ) having an intermediate value. Similarly, PAL did not differ between boys and girls after adjustment for weight and age, but was significantly higher in Maori 


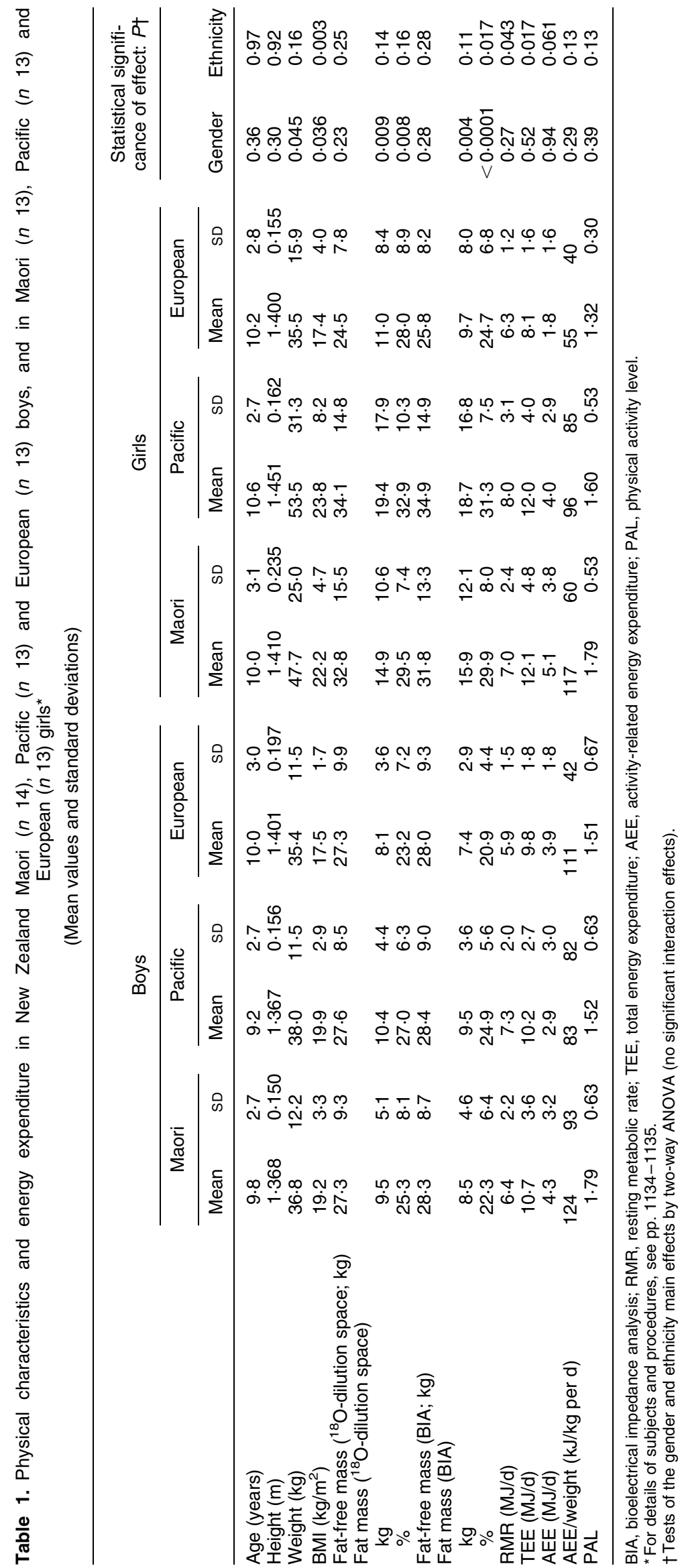




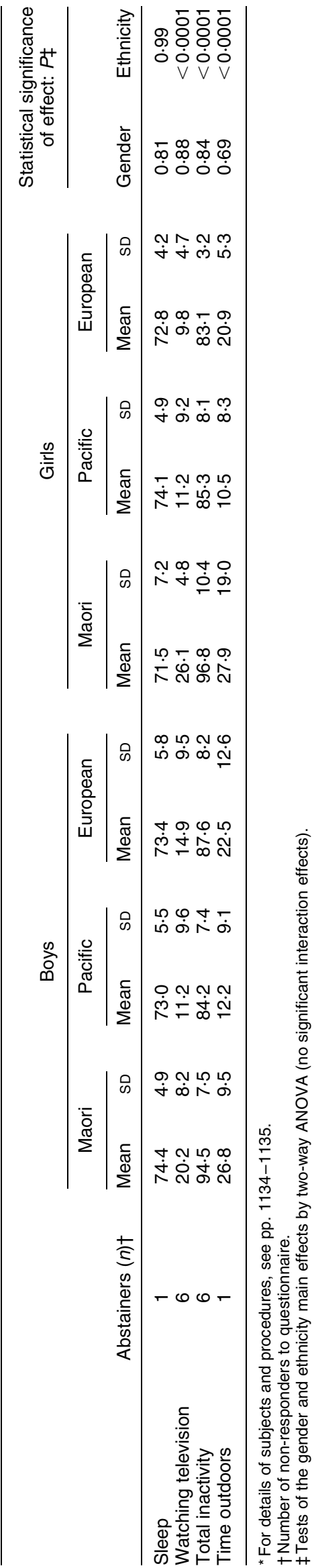

(1.80 (SD 0.51)) than European (1.45 (SD 0.53), $P=0.018)$ children, while Pacific children had an intermediate value (1.61 (SD 0.52)).

For boys, PAL and AEE/weight were negatively correlated with $\%$ body fat $(r-0.43, P=0.006 ; r-0.52$, $P=0.0006$ respectively), while for girls no significant correlations were found $(r-0.02, P=0.90 ; r-0.10, P=0.53$ respectively). Very similar results were obtained using $\%$ body fat obtained from bioelectrical impedance measurements.

Table 2 summarises reported time spent in inactivity and outdoors expressed in $\mathrm{h}$ per week as assessed by questionnaire for gender and ethnic subgroups. Not all children responded to these questions. We did not analyse data relating to time spent in sitting- and standing-type activities, walking, and running, because of the low response rate for these questions. The mean values for $h$ per week spent sleeping were similar across gender and ethnic subgroups. Time spent watching television was similar for boys and girls, but varied significantly with ethnicity $(P<0.0001)$, with Maori children spending more time watching television than Pacific or European children. Total inactivity, as the sum of sleep and television times, shows this same pattern. Similarly, time spent outdoors was similar for boys and girls, but differed across ethnic groups $(P<0 \cdot 0001)$, where Pacific Island children reported less time outdoors than the other two groups.

\section{Discussion}

The results of the present study of seventy-nine children showed that $\%$ body fat increased with age in girls, but not in boys; for boys, but not girls, a higher \% body fat was associated with lower PAL and AEE normalised by body weight. In a study of children aged between 6 and 9 years, Ball et al. (2001) also showed that PAL and \% body fat were inversely related for boys, but not for girls. Our present work extends this age range to 14 years.

Our present results for PAL (1.57 for girls and 1.67 for boys) are not dissimilar to the values reported by Black et al. (1996) for children in the 7-12-year age group (1.68 and 1.74 respectively). The mean ages of these children were 9.2 years for girls and 9.8 years for boys. Our present results for average TEE for the European children ( 8.1 and $9.8 \mathrm{MJ} / \mathrm{d}$ for girls and boys respectively) were almost identical to those reported by Black et al. (1996) for white children $(8.0$ and $9.8 \mathrm{MJ} / \mathrm{d})$.

In European children of pre-school age, Davies et al. (1995) have shown a significant inverse relationship between physical activity and \% body fat for both boys and girls. The uncoupling of physical activity and body fatness occurring in older girls, as found by Ball et al. (2001) and the present study, has also been observed in adults in a study by Westerterp \& Goran (1997) and by analysis of data from a study we have previously published (Rush et al. 1999). Longitudinal studies are required to look at the long-term implications of these findings, as it is important that interventions are made at critical periods of growth and development in children.

In the present study we hypothesised that the higher rates of obesity found in school-aged children of Maori 
and Pacific descent compared with European (Tyrrell et al. 2001) would be reflected in lower levels of physical activity and AEE. Our present results did not support this hypothesis. We found higher BMI in Maori and Pacific children compared with European children. However, PAL and AEE were higher in Maori than European children, after appropriate adjustment for body weight and age. Pacific Island children had intermediate values. We found also that TEE, after adjustment, was highest in the Maori children when compared with the European children, while adjusted RMR was similar across the ethnic groups. A qualitative assessment of activity patterns showed, however, that Maori children tended to be more inactive than Pacific or European children.

Ethnic differences in resting energy expenditure have been hypothesised to explain, at least in part, racial differences in the development of obesity. Evidence from several studies suggests that US black children have lower adjusted RMR than their white counterparts in pre-pubertal and pubertal age ranges (Yanovski, 2001); our previous work in young women in New Zealand has shown a lower RMR in Pacific and Maori subjects compared with European (Rush et al. 1997) subjects. In the current study, the first to investigate RMR differences between European and Maori or Pacific Island children resident in New Zealand, adjusted RMR tended to be higher in Pacific children than Maori or European children, although not reaching statistical significance.

A limitation of our present study is that we did not determine pubertal stage in the children, which, particularly if pubertal development differed between ethnic groups, could influence the observed relationships. To address this issue, we have carried out the comparisons across ethnic groups including only girls aged $\leq 10$ years and boys aged $\leq 12$, and our conclusions are not altered. In a random survey of $>3400$ New Zealand children (Parnell et al. 2003) $3 \%$ of Maori, $1 \%$ of Pacific and $0 \%$ of European girls were aged $\leq 10$ years at menarche. Significantly higher TEE after adjustment was found in Pacific children, with European with Maori children having intermediate values. Adjusted AEE and PAL were significantly higher for both Pacific and Maori compared with European children. For adjusted RMR, again neither gender nor ethnicity were significant factors.

While the relationship between childhood fatness and the risk of adult obesity is not strong, the review by Power et al. (1997) concludes that fatter children are more likely to have an elevated risk of adult obesity. A longitudinal study in New Zealand of European children followed from childhood to 21 years old came to a similar conclusion: a high BMI in childhood predicts overweight at 21 years old (Williams, 2001). The mean BMI of boys at 9 years old in their cohort was $16 \cdot 3$ and for girls $16.4 \mathrm{~kg} / \mathrm{m}^{2}$. The Europeans in our present study at a mean age of $10 \cdot 0$ years had similar BMI values (boys $17 \cdot 5$, girls $17.4 \mathrm{~kg} / \mathrm{m}^{2}$ ). For the Maori and Pacific groups, the BMI were markedly higher (boys $21 \cdot 1$, girls $21.8 \mathrm{~kg} / \mathrm{m}^{2}$ ). In the study of 2273 Auckland schoolchildren (aged 5.0 $-10 \cdot 9$ years) by Tyrrell et al. (2001), high rates of obesity in European, Pacific Island and Maori ethnic groups were found, particularly if a threshold of $30 \%$ body fat was used to define obesity, as recommended by
Ellis (1996). With this criterion they found the proportion of children classified as obese was (\%): European 20, Maori 46, Pacific Island 49; in the present work we found (\%): European 27, Maori 33, Pacific Island 46.

In the Third National Health and Nutrition Examination Survey of 4069 US children aged 8-16 years, a positive relationship was found between television watching and obesity (Crespo et al. 2001), but we were not able to show this in our relatively small sample of children with more direct measurements of body fatness. Our present children watched on average $>2 \mathrm{~h}$ of television per d, a value similar to that found in the US study. Quantification of physical activity requires high compliance and understanding from the volunteers, as all daily activity needs to have frequency, intensity and time spent recorded. We provide objective support for observations from New Zealand surveys that report that Maori children are more likely than non-Maori to be regularly active, but more Maori than non-Maori appear to be sedentary (Ministry of Health, 2002).

A low response rate to questions concerning out-ofschool activities limited the information derived from our questionnaire. In future studies considerable effort needs to be expended in increasing this rate of response. Qualitative information, yielding time spent in activity and inactivity, provides complementary data to quantitative energy expenditure information or daily energy cost of activity. Either or both aspects may be important in the development of obesity in children (Goran et al. 1997).

In summary, our present results on the components of energy expenditure in Maori, Pacific and European children do not explain the higher rates of obesity found in the non-European groups. Additional information relating to total energy intake in these children and longitudinal studies to investigate the rate of body fat change during growth may be required to clarify the role of ethnicity in the development of childhood obesity. Our present study shows that, in the years before and including puberty, a gender dimorphism occurs both in the relationship between age and body fatness and the relationship between AEE and body fatness.

\section{Acknowledgements}

We gratefully acknowledge the contributions of the multidisciplinary teams from the University of Auckland, Massey University and the Auckland University of Technology to this part of the Validation Study for the National Children's Nutrition Survey. The ongoing support and guidance of the Kaitiaki group for the appropriate collection and use of Maori data is acknowledged. The parents and children who took part and gave of their time and interest are recognised as the most important contributors to the present study. We acknowledge the financial support of the Ministry of Health, the Maurice and Phyllis Paykel Trust and the Auckland University of Technology.

\section{References}

Ball EJ, O'Connor JO, Abbott R, et al. (2001) Total energy expenditure, body fatness and physical activity in children aged 6-9y. Am J Clin Nutr 74, 524-528. 
Bathgate M, Alexander D, Mitikulena A, Borman B, Roberts A \& Grigg M (1994) The health of Pacific islands people in New Zealand. Wellington: Pacific Health Commission.

Bell AC, Swinburn BA, Stewart A, Jackson R, Tukuitonga C \& Tipene-Leach D (1996) Ethnic differences and recent trends in coronary heart disease incidence in New Zealand. NZ Med $J$ 109, 66-68.

Black AE (1996) Physical activity levels from a meta-analysis of doubly labeled water studies for validating energy intake as measured by dietary assessment. Nut Rev 54, 170-174.

Black AE, Coward WA, Cole TJ \& Prentice AM (1996) Human energy expenditure in affluent societies: an analysis of 574 doubly-labelled water measurements. Eur J Clin Nutr 50, $72-92$.

Crespo CJ, Smit E, Troiano RP, Bartlett SJ, Macera CA \& Andersen RE (2001) Television watching energy intake and obesity in US children. Results from the Third National Health and Nutrition Examination Survey 1988-1994. Arch Pediatr Adolesc Med 155, 360-365.

Davies PSW \& Coward WA (1994) Total energy expenditure and energy intake in the pre-school child: a comparison. $\mathrm{Br} J$ Nutr 72, 13-20.

Davies PSW, Gregory J \& White A (1995) Physical activity and body fatness in pre-school children. Int J Obesity 19, 6-10.

Ellis KJ (1996) Measuring body fatness in children and young adults: comparison of bioelectric impedance analysis, total body electrical conductivity and dual-energy X-ray absorptiometry. Int J Obes 20, 866-1873.

Fomon SJ, Haschke F, Ziegler EE \& Nelson SE (1982) Body composition of reference children from birth to age 10 years. Am J Clin Nutr 35, 1169-1175.

Freedman DS, Srinivasan SR, Valdez RA, Williamson DF \& Berenson GS (1997) Secular increases in relative weight and adiposity among children over two decades: the Bogalusa Heart Study. Pediatrics 99, 420-426.

Going SB, Levin S, Harrell J, et al. (1999) Physical activity assessment in American Indian schoolchildren in the Pathways study. Am J Clin Nutr 69, Suppl., 788S-795S.

Goran MI, Hunter G, Nagy TR \& Johnson R (1997) Physical activity related energy expenditure and fat mass in young children. Int J Obes 21, 171-178.

Goran MI \& Nagy TR (1996) Effect of the pre-testing environment on measurement of metabolic rate in children. Int $J$ Obes 20, 83-87.

Huszczuk A, Whipp BJ \& Wasserman K (1990) A respiratory gas exchange simulator for routine calibration in metabolic studies. Eur Respir J 3, 465-468.

Janz KF, Witt J \& Mahoney LT (1995) The stability of children's physical activity as measured by accelerometry and self report. Med Sci Sports Exerc 27, 1326-1332.

Kriska AM, Knowler WC, LaPorte RE, et al. (1990) Development of questionnaire to examine relationship of physical activity and diabetes in Pima Indians. Diabetes Care 13, 401-411.

Lohman TG (1986) Applicability of body composition techniques and constants for children and youths. Exerc Sports Sci Rev 14, 325-357.

Ministry of Health (2002) Healthy Action - Healthy Eating: Oranga Puamu - Oranga Kai: Towards an Integrated Approach to Physical Activity Nutrition and Healthy Weight for New Zealand, p 73. Wellington: Ministry of Health.

Parnell W, Scragg R, Wilson N, Schaaf D \& Fitzgerald E (2003) NZ Food: NZ Children - A Report on the Nutritional and Health Status of New Zealand Children. Wellington: Ministry of Health.

Pate RR, Baranowski T, Dowda M \& Trost SG (1996) Tracking of physical activity in young children. Med Sci Sports Exerc 28, 92-96.

Power C, Lake JK \& Cole TJ (1997) Measurement and long-term health risks of child and adolescent fatness. Int J Obes 21, 507-526.

Rush EC, Plank LD \& Coward WA (1999) Energy expenditure of young Polynesian and European women in New Zealand and relations to body composition. Am J Clin Nutr 69, 43-48.

Rush EC, Plank LD \& Robinson S (1997) Resting metabolic rate in young Polynesian and Caucasian women. Int J Obes $\mathbf{2 1}$ $1071-1075$.

Rush EC, Puniani K, Valencia ME, Davies PSW \& Plank LD (2003) Estimation of body fatness from body mass index and bioelectrical impedance: comparison of New Zealand European, Maori and Pacific Island children. Eur J Clin Nutr (In the Press).

Schoeller DA \& Jefford G (2002) Determinants of the energy costs of light activities: inferences for interpreting doubly labeled water data. Int J Obes 26, 97-101.

Schutz Y, Weinsier RL \& Hunter GR (2000) Assessment of freeliving physical activity in humans: an overview of currently available and proposed new measures. Obes Res 9, 368-379.

Simmons D, Gatland B, Fleming C, Leakehe L \& Scragg R (1994) Prevalence of known diabetes in a multiethnic community. NZ Med J 107, 219-222.

Trioano RP, Flegel KM, Kuczmarski RJ, Campbell SM \& Johnson CL (1995) Overweight prevalence and trends for children and adolescents. The National Health and Nutrition Surveys. Arch Pediatr Adolesc Med 149, 1085-1091.

Tyrrell V, Richards G, Hofman P, Gillies G, Robinson E \& Cutfield W (2001) Obesity in Auckland school children: a comparison of the body mass index and percentage fat as the diagnostic criterion. Int J Obes 25, 164-169.

Westerterp K \& Goran M (1997) Relationship between physical activity related energy expenditure and body composition: a gender difference. Int J Obes 21, 184-188.

Williams S (2001) Overweight at age 21: the association with body mass index in childhood and adolescence and parents' body mass index. A cohort study of New Zealanders born in 1972-1973. Int J Obes 25, 158-163.

World Health Organization (1998) Obesity: Preventing and Managing the Global Epidemic. Geneva: WHO.

Yanovski J (2001) Resting energy expenditure in African American and white children. Am J Clin Nutr 73, 149-150. 